\title{
Survivors of Intimate Partner Violence as Advocates for Social Change
}

\section{Christine E. Murray and Kelly King}

The University of North Carolina at Greensboro

\author{
Allison Crowe \\ East Carolina University \\ Paulina Flasch \\ University of Central Florida
}

\begin{abstract}
Intimate partner violence is a major public health issue that presents numerous potential challenges and negative consequences for survivors. The external barriers and systemic oppression that contribute to these challenges and consequences are potentially relevant factors for counselors to address in social justice advocacy efforts. In addition to advocacy initiatives led by counselors, counselors can support their clients who have experienced IPV victimization to engage in self-advocacy, as well as advocacy efforts designed to promote positive social change. This study examines how survivors of IPV $(n=123)$ think about themselves as potential or actual advocates, as well as survivors' considerations for engaging in advocacy efforts. We apply content analysis methodology to identify themes within respondents' qualitative responses to an advocacy-related question on an electronic survey on the process of overcoming abuse. The following themes emerged: the significance of survivors' involvement in advocacy, survivors' personal qualities and skills required for effective advocacy, validation of survivors' right to choose whether or not to engage in advocacy, and examples of survivors' large and small-scale advocacy efforts. The ACA Advocacy Competencies are then used to organize and operationalize survivors' perceptions and experiences related to their involvement in advocacy efforts. The unique opportunities and challenges that survivors may encounter when they engage in advocacy initiatives at the individual, community, and societal levels are considered. This study aims to expand the concept of self-advocacy to survivors of IPV and other similarly marginalized groups, highlighting the potential for personal empowerment and social change.
\end{abstract}

Keywords: intimate partner violence, domestic violence, advocacy, ACA Advocacy Competencies, social justice 


\section{Survivors of Intimate Partner Violence as Advocates for Social Change}

Advocacy is increasingly considered an essential activity for counselors (Toporek, Lewis, \& Crethar, 2009). The increased attention to this counselor role is translating into a growing body of literature on effective advocacy and client empowerment strategies. The primary focus within both research and training to date has been on advocacy by professionals, with much less attention being paid to advocacy efforts by clients themselves. However, the American Counseling Association's (ACA) Advocacy Competencies (Lewis, Arnold, House, \& Toporek, 2002) emphasize the importance of counselors supporting client populations as they advocate for themselves. Specifically, competencies within the Client/Student Empowerment domains encourage clients to develop personal agency and a critical consciousness (Ratts \& Hutchins, 2009). These competencies include: (a) helping clients identify barriers in their social context, (b) training clients in specific skills that allow them to engage in self-advocacy, and (c) supporting clients as they develop and implement self-advocacy action plans (Lewis et al., 2002). In essence, counselors can collaborate with clients to advocate for changes that could help others and themselves.

The purpose of this article is to examine self-advocacy with survivors of intimate partner violence (IPV). Rates of IPV are high within the general population, and higher still within clinical populations. As a result of the dynamics of abuse and the stigma that survivors often face within their communities and the broader society, many survivors of IPV experience oppression and external barriers that can hinder the progress they make in counseling (Crowe \& Murray, 2015; Murray, Crowe, \& Overstreet, under review). Our previous research and community-engaged outreach addressing the stigma surrounding IPV explored survivors' desire to use their experiences to help others (Crowe \& Murray, 2015; Murray, Crowe, \& Brinkley, 2015), a desire that prompts many survivors of IPV to engage in various advocacy efforts. This article presents the findings of a study in which survivors of past abusive relationships shared their attitudes and experiences related to engaging in advocacy initiatives. This information can assist counselors working with members of this population, as well as others who have experienced oppression and trauma, to understand some of the unique challenges and opportunities that arise when survivors engage in advocacy. In order to provide a framework for these efforts, the authors of this article will (a) review the dynamics of IPV, (b) examine the Advocacy Competencies put forth by ACA (Lewis et al., 2002), (c) present the findings of the present study, and (d) discuss implications for practice and future research.

\section{Advocacy through the Lens of IPV}

Intimate partner violence is defined as "physical, sexual, or psychological harm by a current or former partner or spouse" (Centers for Disease Control and Prevention, CDC, 2014, paragraph 1). The CDC's recent National Intimate Partner and Sexual Violence Survey (Black et al., 2011) revealed that over $30 \%$ of women and over $25 \%$ of men in the U.S. have experienced some form of physical or sexual abuse and/or stalking in an intimate relationship at some point in their lives, and rates of psychological IPV are even higher, with a prevalence rate of almost $50 \%$ for both women and men (CDC, 2014). People who have been victimized by an intimate partner are at risk for experiencing a host of negative consequences, which may impact their physical health, their mental wellbeing, their economic and career self-sufficiency, and their 
relationships (Murray \& Graves, 2012). In light of the impact of the trauma they have experienced, an empowerment approach to working with survivors of IPV is recommended. Empowerment is conceptualized as a process, rather than an outcome; in other words, clients' choices are validated throughout counseling (Morgan \& Coombes, 2013). The empowerment process is psychoeducational in nature, where counselors support their clients in (a) understanding the forms of oppression impacting their lives, (b) identifying their personal goals and values, and (c) establishing a means of obtaining these goals (Morgan \& Coombes). This model underscores the importance of self-advocacy through clients' actively making choices about their futures and potentially advocating for broader social change (Morgan \& Coombes). In this article, the authors aim to extend the existing literature on client empowerment by examining ways that clients can engage in self-advocacy in order to counteract the oppression that they face within a variety of social contexts.

Intimate partner violence as a societal issue and survivors provide an illustrative context for considering social justice advocacy efforts. We see many parallels between this form of oppression and other forms, including their systemic causes, their multigenerational impact, and the largely controversial space they occupy within public discourse. To fully address the needs of clients facing oppression, counselor-advocates must develop an understanding of clients' particular social, political, economic, and cultural systems and the dynamics that prohibit their pursuit of well-being (Toporek et. al, 2009). With this baseline understanding, there are many avenues for effective intervention including empowerment and social action strategies. In light of these dynamics, advocacy efforts to address IPV may occur at many different levels, including individual (e.g., to advocate for support and access to resources for individual survivors), community (e.g., to advocate for changes to community and/or organizational changes to more effectively prevent and respond to IPV), and societal (e.g., to raise awareness about the realities of IPV within the general population) efforts.

\section{Applying the ACA Advocacy Competencies to Clients' Advocacy Involvement}

Although the ACA Advocacy Competencies (Lewis et al., 2002) focus primarily on the function of counselors, their emphasis on client empowerment offers a unique lens through which to examine advocacy within client populations. Ratts and Hutchins (2009) outlined three realities that make the ACA Advocacy Competencies (Lewis et al.) necessary for comprehensive counseling: (a) oppression is widespread and undermines human development, (b) a focus on individual factors minimizes the importance of contextual factors, and (c) there is a need in the profession for clear, concrete social justice strategies. The Advocacy Competencies include client/student, school/community, and public arena areas of advocacy (Lewis et al.). At each level, counselors are able to act with or act on behalf of their clients. Thus, there are six categories for social justice actions encompassed within the Advocacy Competencies: client/student empowerment, client/student advocacy, community collaboration, systems advocacy, public information, and social/political advocacy. For the current study, our focus was on the client level of empowerment and advocacy, as we aimed to illuminate clients' potential abilities and desires to be agents of social change. Importantly, the client level of ACA's advocacy competencies has implications for a client's own healing through self-advocacy and social contributions. 
Client/student empowerment activities are those that address a counselor acting with a client to meet their needs in a more individualized fashion (Toporek et al., 2009). We have adapted the language of these competencies (Lewis et al., 2002) to reflect the objectives of survivors of IPV in empowering themselves/others in the following ways. Survivors can embrace and teach selfadvocacy by:

1. Identifying strengths and resources of victims/survivors

2. Identifying social, political, economic, and cultural factors that impact victims/survivors

3. Recognizing how an individual's behavior and concerns reflect responses to systemic and/or internalized oppression

4. Helping the individual victim/survivor identify the external barriers that affect his or her development

5. Offering victims/survivors training in self-advocacy skills

6. Helping victims/survivors develop self-advocacy plans

7. Assisting victims/survivors in carrying out plans

These context-specific competencies enable survivors to act with other people who are a part of their marginalized group. This type of advocacy work can be realized in many different ways, as determined by the survivor's goals, interests, skills, and willingness to be an advocate. However, we were unable to locate any prior research that specifically looked at the advocacy skills, attitudes, and experiences among survivors of IPV, and, therefore, the current study represents the first known research-based exploration of the contributions that survivors of IPV can make toward advocating for social change that addresses IPV at the societal level. In the next sections, we describe the study's methods and the themes identified in participants' responses regarding their perceptions and experiences with advocacy efforts.

\section{Method}

\section{Participant Recruitment and Demographic Characteristics}

Participants were 123 survivors of past abusive relationships who participated in an anonymous electronic survey between April $21^{\text {st }}, 2014$, and July $9^{\text {th }}, 2014$. Participants were recruited through a variety of electronic means, which included posting notices about the survey on a variety of social media sites that are relevant to the population of survivors of IPV (e.g., domestic violence service agencies, national domestic violence advocacy organizations, and peer support groups for survivors) and sending e-mails to personal and professional contacts. Notices about the survey included requests for people to forward information about the study to others they know who may have been interested in participating, thereby using a snowball sampling process. As a result of the recruitment methods used, the final sample should be considered a convenience sample. In order to be eligible to participate in the study, participants had to have self-reported that they had been in a past intimate relationship that included some form of intimate partner violence (i.e., emotional/psychological, physical, and/or sexual abuse), but that they had been out of any abusive relationship for at least two years. The two-year minimum for being out of any abusive relationships was required for two main reasons. First, this time frame was required as an ethical protection for participants. As we were asking them to report on past experiences that were emotionally salient and potentially traumatic, we 
believed the two-year time frame would generally offer participants adequate distance from their experiences with abuse to minimize the potential for emotional distress in completing the survey. Second, the two-year time frame was selected to reflect our goal of including a sample that had successfully demonstrated an ability to sustain nonviolent lives and relationships. It was our assumption that two years of living free from abuse is a substantially long time-frame to demonstrate that survivors in our research were free from abuse in a lasting manner. Participants also had to have been at least 21 years old and able to read the survey, which was written in the English language.

The average age of participants was 41.0 years $(S D=11.5)$. The vast majority $(n=117$; $95.1 \%)$ of participants were female. Only three participants $(2.6 \%)$ were male. One participant reported "other" as their gender identity (which they specified as "gender fluid"), and two participants did not report their gender. Participants' racial/ethnic backgrounds were as follows: African American/Black $(n=5 ; 4.1 \%) ;$ Asian $(n=1 ; 0.8 \%)$, Caucasian/White $(n=103$; $83.7 \%)$, Hispanic/Latino/Latina $(n=11 ; 8.9 \%)$, Native American $(n=3 ; 2.4 \%)$, and Other $(n$ $=4 ; 3.3 \%$ ) (Note: Participants could select all ethnic backgrounds that applied, so the sum of percentages is greater than $100 \%$ ). The sample was geographically diverse, with participants representing 31 states in the U.S., plus the District of Columbia, plus nine other countries or territories (including Australia, Canada, England, Spain, and Cameroon).

Participants were also diverse in their educational backgrounds and income levels. The highest levels of education completed by participants were as follows: high school diploma/GED ( $n=$ $37 ; 30.0 \%)$, Associate's degree $(n=20 ; 16.3 \%)$, Bachelor's degree $(n=41 ; 33.3 \%)$, Graduate degree $(n=18 ; 14.6 \%)$, other $(n=5 ; 4.1 \%)$, and not reported $(n=2 ; 1.6 \%)$. Regarding income, participants reported their current household income levels as follows: under $\$ 30,000$ $(n=52 ; 42.3 \%), \$ 30-59,000(n=38 ; 30.9 \%), \$ 60-100,000(n=20 ; 16.3 \%)$, and over $\$ 100,000$ ( $n=12 ; 9.8 \%$ ) (Note: one participant did not report their income level).

Participants reported their current relationship statuses as follows: married ( $n=29 ; 23.6 \%$ ); single $(n=25 ; 20.3 \%)$; in a committed relationship, living together $(n=21 ; 17.1 \%)$; divorced ( $n=14 ; 11.4 \%)$; in a committed relationship, not living together $(n=13 ; 10.6 \%)$; separated $(n=8 ; 6.5 \%)$; dating but not in a committed relationship $(n=5 ; 4.1 \%)$; other $(n=5 ; 4.1 \%)$; in a legally-recognized civil union/domestic partnership, not married $(n=2 ; 1.6 \%)$; and not reported $(n=1 ; 0.8 \%)$. Ninety participants $(73.2 \%)$ reported that they had children.

Participants were asked to describe their past experiences with IPV in intimate relationships, focusing in-depth on their most recent relationship in which they experienced IPV. First, participants reported the number of relationships in which they had experienced any form of IPV. The most common response was one relationship ( $n=63 ; 51.2 \%)$, and the highest number of abusive relationships reported was five, which was reported by seven participants $(5.7 \%)$. The average number of abusive relationships among participants was 1.83 (SD = 1.12). The following details summarize participants' reports on their most recent relationships that included any form of IPV. Six participants (4.9\%) reported that their partners were of the same gender, and 115 participants (93.5\%) reported that their partners were a different gender. Most participants in this study were describing abusive relationships in which the victims/survivors were female and the perpetrators were male. Rounded to the nearest year, the range in the length of participants' relationships was 0 to 29 years (Mean $=8.14$; $S D=$ 
6.69). Participants described the highest level of commitment in these relationships as follows: dating but not in a committed relationship ( $n=6 ; 4.9 \%)$; in a committed relationship, not living together ( $n=15 ; 12.2 \%)$; in a committed relationship, living together $(n=36 ; 29.3 \%)$; married ( $n=61 ; 49.6 \%)$; in a legally-recognized civil union, not married $(n=2 ; 1.6 \%)$; and other $(n=3 ; 2.4 \%)$. About half $(n=62 ; 50.4 \%)$ of the participants reported that they had children with their abusive partners.

Participants described the nature of abuse they experienced in these relationships. The vast majority of participants $(n=102 ; 82.9 \%)$ reported that they had experienced physical abuse, all but two participants $(n=121 ; 98.4 \%)$ reported experiencing emotional/psychological abuse, and over two thirds of participants experienced sexual abuse $(n=87 ; 70.7 \%)$. Fifty-two participants $(42.3 \%)$ provided open-ended descriptions of other types of abuse they experienced, which included spiritual abuse, stalking, making threats to their children, financial abuse, and cyber bullying. Only $46(37.4 \%)$ of the participants reported that their abusive partners received any form of legal punishments or sanctions as a result of their abusive behaviors. As an eligibility requirement, none of the participants had been involved with their abusive partners for at least two years. However, thirty-seven (30.1\%) participants still had some form of current contact with their former abusive partners. The average length of time it had been since participants' relationships with these partners had ended was 8.14 years (SD = 7.58).

\section{Procedures and Survey Instrumentation}

The electronic survey was hosted on the secure Qualtrics Internet-based survey hosting platform. As an incentive for participation, all participants who completed the full survey were eligible to enter a drawing for one of two $\$ 50$ store gift cards. Participants were able to enter the drawing without having their identities linked to their responses, as those who completed the full survey were directed to send a separate e-mail to the lead researcher in order to enter the drawing. The study was approved by two universities' Institutional Review Boards prior to data collection began, and participants were required to read and agree to the terms of an informed consent document before they were able to enter the survey web-site. The survey was estimated to take about 20 minutes to complete, although participants who wrote in-depth responses to the open-ended questions would have taken additional time to complete the survey. Participants were allowed to choose not to answer any questions they did not feel comfortable answering.

The survey questionnaire was developed for this study. It began with an eligibility questionnaire, and participants who did not meet the eligibility criteria for the study were not able to enter the full survey website. Participants who met the eligibility criteria and agreed to the terms of the informed consent document were presented with the full survey, which included three parts. Part One asked participants to describe their demographic characteristics. Part Two included background questions about participants' experiences with IPV, focusing in particular on their most recent relationship in which they experienced any form of abuse. The third and final part of the survey included a series of questions about participants' experiences with overcoming past abuse, which was the focus of the larger study through which the data presented here about advocacy were drawn. The open-ended questions included in this section address the following topics: (a) participants' views about what it means to overcome past 
abuse; (b) critical moments during which participants decided they were going to leave their abusive relationships once and for all; (c) metaphors participants used to describe their processes of overcoming abuse; (d) the changes that participants made in their lives to overcome past abuse, (e) the messages they would want to send to people who have recently left an abusive relationship, and (f) any other insights they wished to share that were relevant to the topics addressed on the survey. In addition, the following open-ended question was included to solicit participants' perceptions and experiences related to advocacy work:

Some of the participants in the authors' previous research described how they were motivated to use their past experiences with abuse to become an advocate to helping others who have been abused. Being an advocate means different things to different people, and it could come in the form of paid and/or volunteer work with victims/survivors of domestic violence, providing support through a community or religious organization, writing letters to the editor, speaking about their experiences with others in the community, and other formal and informal forms of advocacy. (a) To what extent do you view yourself as an advocate?; (b) If you view yourself as an advocate, what steps did you take to move from being a survivor to becoming an advocate?; and (c) If you do not yet view yourself as an advocate but would like to become one, what skills or experiences do you think you need before you will feel ready to take on that role?

For the current study, only participants' responses related to the question about advocacy were examined. The survey concluded by providing participants with information about how to enter the incentive drawing and with resources for more information from national organizations working to address IPV (e.g., the National Coalition Against Domestic Violence and the National Domestic Violence Hotline). These resources were also provided in the event that any of the participants felt they needed additional support following completion of the survey.

\section{Data Analyses}

Because of the limited dataset used for this study (i.e., responses to one question on a larger survey), a basic content analysis procedure was used to categorize the data into themes. Although a more in-depth content analysis process should be considered in future research (e.g., the procedures suggested by Stemler, 2001), the current analyses provide a preliminary analysis of the themes in the advocacy-related experiences and perspectives of survivors of intimate partner violence. A conventional content analysis process was used to compile the participants' responses to the advocacy-related question into themes. Conventional content analysis, according to Patton (2002), "attempts to identify core consistencies and meanings" (p. 453) and is used when the existing theory or literature on a topic is limited and pre-existing categories do not exist (Hsieh \& Shannon, 2005). The researchers began with an initial readthrough of all the data. From there, an initial list of themes related to participants' perceptions of and experiences with advocacy efforts was developed. From there, relevant participant quotes were grouped within each theme. All researchers reviewed the themes and quotes that were listed within each theme. The themes with some illustrative quotes are presented in the next section. 


\section{Results}

A total of 79 participants provided responses to the survey question on advocacy, representing $64.2 \%$ of the sample. Preliminary analyses using a t-test and ANOVAs were conducted to determine if there were demographic differences between participants who completed the advocacy question and those who did not. No statistically significant differences were found for any of the following characteristics: age $(t=1.306, \mathrm{df}=119, p=0.194)$, gender $(\mathrm{F}=0.203, p$ $=0.653)$, whether they had children $(F=1.103, p=0.296)$, ethnicity $(F=.192, p=0.662)$, or highest level of education ( $F=0.005, p=0.943$ ). There was, however, a statistically significant difference, at the $p<.05$ level, between those who did and did not complete the advocacy question based on household income $(F=4.579, p=0.034)$. As shown in Table 1, there was diversity in participants' household income levels within both groups, but overall there were more participants in the higher income levels among those participants who answered the advocacy question compared to those who did not.

Table 1

\section{Household Income Between Participants Completing and Not Completing the Advocacy Question}

\begin{tabular}{|c|c|c|c|c|}
\hline \multicolumn{5}{|c|}{ Household Income Level } \\
\hline Group & Under $\$ 30,000$ & $\$ 30-59,000$ & $\$ 60-100,000$ & Over $\$ 100,000$ \\
\hline $\begin{array}{c}\text { Completed } \\
\text { Advocacy } \\
\text { Question }\end{array}$ & $n=22$ & $\mathrm{n}=15$ & $\mathrm{n}=6$ & $\mathrm{n}=1$ \\
\hline $\begin{array}{l}\text { Did Not } \\
\text { Complete } \\
\text { Advocacy } \\
\text { Question }\end{array}$ & $\mathrm{n}=30$ & $n=23$ & $\mathrm{n}=14$ & $\mathrm{n}=11$ \\
\hline Total & $n=52$ & $\mathrm{n}=38$ & $n=20$ & $\mathrm{n}=12$ \\
\hline
\end{tabular}

The advocacy question was one of the final items on the survey; thus, it is possible that some participants were experiencing fatigue by the end of the survey, and they did have the option to skip any questions they did not want to answer. Some of the responses did not fall into any of the themes discussed below, especially items that were very brief or general in nature, such as "Yes!" and "I don't know." The other responses were categorized into the following themes: (a) the important voice of survivors in advocacy efforts; (b) survivors' personal characteristics and skills needed to engage in advocacy efforts; (c) validation of survivors' right to choose whether or not to engage in advocacy efforts; (d) and examples of survivors' advocacy initiatives, including both large-scale and smaller-scale efforts. 


\section{The Important Voice of Survivors in Advocacy Efforts}

Eight participants' responses provided examples of the unique and important contributions that survivors can make in advocacy efforts to address IPV. In particular, participants emphasized that their personal experiences with abuse provide them with a deep understanding of the dynamics of abuse that inform their advocacy work. As one participant said, "To be able to say, 'I know' and really mean it means a world of difference." Participants noted that their personal experiences could help to provide inspiration and validation to others who have been abused, as is illustrated in the following quotes:

- "I raise awareness and share my own experiences openly and proudly in the hope that other who hear it will understand that they aren't alone in this."

- "I think survivors are the best resource for other survivors because we know what we wish people would tell us."

- "I would like to become an advocate. I think that I have learned so much from my experience and could help others overcome their struggle as well."

To be effective at using their own experiences in advocacy work, participants noted the importance of survivors experiencing healing themselves first (e.g., "I think it's a recovery process and a person should be in a healthy relationship before they can really mentor another as a role model"), as well as ensuring that they do not assume that everyone's experiences will be exactly the same as their own. Accordingly, one participant offered the following advice: "Being able to advocate is taking my experiences and using them to help others without putting my experience onto them. Their experience is different than mine. Of course there are similarities but I need to hear their story without clouding it with mine." Overall, the quotes in this theme highlight the significant insights and personal convictions that survivors can bring to IPV-related advocacy work.

\section{Validation of Survivors' Right to Choose Whether or Not to Engage in Advocacy}

Despite the important role that survivors can play in advocacy efforts, several participants noted that survivors may not be interested in or ready to engage in advocacy efforts, and 14 statements fell into this category. Some participants expressed that they simply were not interested in taking on an advocacy role (e.g., "I do not want to be an advocate."). Others stated that they could envision themselves taking on advocacy, but they did not think that they were ready to do so yet (e.g., "I do not feel I am yet strong enough to be an advocate. Maybe in time, but not yet;" and "Not an advocate yet. May be one in the future"). Participants provided examples of the reasons that survivors may not be interested in the advocacy role. First, one participant said that she did not think she would be effective in that role (i.e., "I enjoy helping others but do not believe I would be an effective advocate"). Second, participants said that some aspects of advocacy work would be more or less challenging for them to take on, as reflected in the following quote: "I view myself as a political advocate, but would not be comfortable working with individuals." One important reason about which participants expressed caution about engaging in advocacy efforts was the emotional toll this work could place upon them. As one participant said, "I would love to be an advocate, but I know I need to be able to hear others stories without triggering myself." Another said, "I feel too powerfully 
others pain and it hurts me." For all of these reasons, this theme provides a reminder of the importance of honoring survivors' choice as to whether engaging in advocacy efforts is appropriate and safe for them at any given point in time.

\section{Survivors' Personal Characteristics and Skills Needed to Engage in Advocacy Efforts}

Eight participants described the personal characteristics or skills they viewed as important to their ability to engage effectively in advocacy efforts. The main personal characteristics noted were an ability to be open with others (e.g., "I would love to help anyone who feels they deserve or can't get away from abuse. I am in the process of learning to come out of my shell"), a commitment to personal growth (e.g., "I took the responsibility on myself to become a better person which is defined by me), and a personal commitment and dedication to becoming an advocate (e.g., "I believe that I was destined to do this work").

Regarding skills, one participant said that the lack of skills could be a barrier to engaging in advocacy efforts (i.e., "I don't know if I have skills"). Others noted that they believed that advocacy skills could be learned, such as the participant who said, "I do not see myself as an advocate but I think I could be and would be interested in how to become one." Some of the skills that participants noted could prove useful to advocacy initiatives included writing (i.e., "I am a writer and I would like to write about abusive relationships and situations to expose what few people realize is going on behind the cover of darkness, shame, and fear") and active listening skills (i.e., "Listen carefully, be gentle and let the other person take her own pace.") A unique skill noted by one participant was to "be ok with people looking at you funny/ uncomfortably." This participant went on to say, "You have to deal with not being welcomed and learn how to deliver horrendously toxic information in a receptive way. You have to learn to face extreme hostility and not be reactive but responsive. You HAVE to learn the laws, understand your role/liability and be responsible for the consequences of your actions." Thus, as illustrated by the quotes in this category, participants emphasized the unique blend of personal characteristics and skills that survivors can draw upon when engaging in advocacy initiatives.

\section{Examples of Survivors' Advocacy Initiatives}

Participants provided numerous examples of the types of actions they take that they consider to be a form of advocacy to address IPV. Twenty-three of these statements reflected larger-scale efforts that involved a longer-term commitment of time and resources, and thirteen statements reflected more short-term, less intensive actions that we labeled "smaller-scale efforts." As illustrated in the quotes below, even relatively smaller-scale efforts have the potential for making a major impact.

Large-scale efforts. The following participant quotes illustrate the ways that survivors engage in advocacy efforts that involve speaking engagements, sharing their stories with others, participating in professional and/or volunteer training and work to address IPV, and engaging in advocacy via long-term social media initiatives. 
- $\quad$ "I share my story with women and teens to give them hope...I was a volunteer for (a domestic violence agency) until I became disabled."

- "I speak to others who are dealing with situations I dealt with. Also, work with youth ministry that motivates teens to overcome hardships."

- $\quad$ "I sponsor women in 12 step programs who have been abused and share my experience."

- "I am taking classes to become an advocate. I want to help change the system that is so broken."

- "I volunteer with kids who have been through abuse, and I educate people around me about abusive relationships."

- "My dream now is to make a organization to help woman's like myself to have resources, tools and the guidance to how to get out, help them with housing, work placement, and childcare everything the I never have and legal advise the most reliable tool."

- $\quad$ "I lecture around the country about the dynamics of IPV, surviving IPV, the generational cycle of family violence, and many other facets of this societal and criminal problem. I have assisted law enforcement in writing policies for effective law enforcement response to domestic violence, testify as an expert witness in civil and criminal cases."

- $\quad$ "I started in college, after I'd gotten some therapy on my own, sharing my story with others, and taking steps to help my friends stay out of trouble. And a little network began to grow and never stopped. I now know lots of people who have experienced some sort of trauma and lots of resources to help people deal with them. I've learned that everyone has something that hurt them and by sharing it we all become stronger."

- "I now head up a ...group within our church...We will be working within this group for family violence and adding programs for them also."

- $\quad$ "I have helped other women already, and am going to trainings at my local shelter. My goal is to speak locally and statewide to churches and other organizations that commonly misguide women who are seeking refuge and help from abusive relationships."

- "I have been an advocate in my role as a nurse educator in a large women's clinic, mostly providing information and referrals."

- "I definitely feel that I am an advocate. I am a counselor and use my experiences in many ways. One way I have found myself as an advocate is with women and men leaving abusive relationships."

- "Today I work ... for a DV program... I love my job and frequently share my story with other women. The most gratifying thing I have ever heard is 'hearing your story today made me realize that I am a victim of domestic violence,' that woman's journey to freedom began that day. What a blessing!"

- "I am a full-time paid court advocate for a DV shelter. I had always worked in the legal field and discovered that I really enjoyed working with victims of crime, specifically DV. I have been doing direct services for 5 years and plan on making a career of it."

- $\quad$ "I run a Facebook page and have 1000 followers. I want to grow the page much larger."

- "I am an admin on a Facebook page, our numbers are growing and growing."

- "I also help run DV pages on Facebook that help women once they leave." 
Smaller-scale efforts. One of the less time- and resource-intensive ways that participants reported engaging in advocacy efforts involved shorter-term social media actions (e.g., "I share information on Facebook that has helped others (and made many uncomfortable, but it is a reality that people need to face" and "I share posts, articles, etc. on Facebook and Twitter and Pinterest"). Most of the other smaller-scale advocacy actions that participants identified involved ways they supported others in their immediate social network. Of course, these efforts may not involve large-scale, community-based efforts, but they can have a significant impact on the lives of those they support. One of the interpersonal advocacy activities that participants described included being available to listen to others, such as the following quotes: "I will be there when someone needs me" and "I have told several younger girls that are just starting out in relationships.... what I went through and if they ever have anything at all they can come tell me and I can help them. I can listen without a judgmental ear. I can understand what they are going through." Other participants described the opportunities they took to share their stories with others on a one-on-one basis, such as the participant who said, "Speaking about my abusive past is something that I have done with close friends that were experiencing that beginning phases of partner violence." Others said that they shared advice to others who were involved in abusive relationships (e.g., "When I hear the relationship stories of my friends, I immediately notice the warning signs of abuse. I speak to them clearly and let them know they deserve better and that they should end the relationship" and "I've given people advice sometimes but only if they ask. I know what they are going through, the fear, the pain, the disbelief in their self. I always try and help someone out of a situation if I can"). Finally, participants described ways that they viewed speaking out in conversations with others in their social networks as part of their efforts to advocate to raise awareness about IPV. For example, one participant said, "I speak out against abuse," and another said, "I don't know if it is being an advocate, but I talk about my experience every chance I get, in the hopes that someone within earshot will be encouraged to get help and get away."

\section{Discussion}

For many survivors of IPV, engaging in advocacy efforts is an important way that they transform their past experiences with abuse into opportunities to make a positive difference in the lives of others (Crowe \& Murray, 2015; Murray \& Crowe, in press; Murray \& Crowe, under review; Murray, Crowe, \& Akers, in press; Murray, Crowe, \& Brinkley, 2015; Murray, Crowe, \& Overstreet, under review). Although the current study provides only preliminary information about the ways that survivors of IPV can contribute to advocacy efforts, the findings support the need for counselors to consider how they can best support and partner with survivors in engaging in this work. Importantly, survivor advocacy has the potential to be a therapeutic, empowering experience for clients and to undermine the multi-level oppression faced by other victims and survivors. However, in following the empowerment approach that underlies the best practice approaches to working with survivors of IPV and other forms of trauma, it is important to honor survivors' choices whether and how to engage in advocacy efforts (Morgan \& Coombes, 2013). The results of the current study demonstrate the vast array of options that are available to survivors who may wish to engage in advocacy efforts. In this section, limitations and implications of the present study are discussed, with a particular focus on needs for future research and clinical practice when working with survivors of IPV. 


\section{Summary of Major Findings}

The themes identified in this study provide valuable information to counselors to support their work with survivors of IPV, especially those who are considering or already engaging in advocacy efforts. Participants identified the unique and important contributions that survivors can make to advocacy efforts related to IPV. In particular, their personal experiences with abuse offer them unique insights into the dynamics of abusive relationship and can be especially meaningful to others facing similar relationships. However, survivors of abusive relationships should be supported in making the best decisions for themselves as to whether or not they will engage in advocacy efforts (Morgan \& Coombes, 2013). The risks of emotional distress and re-traumatization related to being involved in this work warrant special consideration, especially in light of the potential for lasting negative impacts of the trauma they have faced upon their mental health (Murray \& Graves, 2012). For those survivors who are interested in engaging in advocacy initiatives, this can involve drawing up and developing new personal characteristics and skills that they engage to enhance their effectiveness at advocating for changes. The participants in this study provided numerous examples of the ways that survivors can engage in advocacy initiatives, both in larger- and smaller-scale initiatives. For some survivors, advocacy can become a full-time endeavor, and yet for others, advocacy efforts may come in the form of supporting one other person or speaking out about IPV on social media or in face-to-face conversations. Taken together, the findings of this study demonstrate the potentially diverse impacts that survivors of IPV can have when they draw upon their experiences and engage in advocacy work.

\section{Limitations}

The data analyzed for this study were drawn from a larger study on the processes through which survivors of IPV overcome past abuse. As such, the focus on advocacy was but one component addressed on this study, and the data were derived from participants' responses to a single question on the survey. Participants likely would have provided greater depth of information and additional contextual information about their responses if this study had been focused solely on IPV-related advocacy. It was not possible to determine whether the nature of the other questions asked on the survey may have had any sort of priming effect that impacted the way they responded to the advocacy-related questions. Thus, future research with a sole focus on advocacy is needed.

Another limitation relates to the convenience sample used. Although efforts were made to recruit a broad, diverse sample, some demographic groups were under-represented in the sample, such as males, queer and trans* individuals and survivors who were from racial/ethnic backgrounds other than Caucasian. This underrepresentation may reflect how individuals with intersecting marginalized identities have less access to resources (i.e. unclear guidelines for accepting trans* people into domestic violence shelters restricts their access) and that ultimately filling out this survey and engaging in counseling or advocacy work are privileged practices. Therefore, there is a need for additional research focusing on advocacy within these specific populations, in order to better understand unique barriers and needs of individuals facing multiple, interacting forms of oppression. In addition, due to the fact that the majority of participants were Caucasian, it is not possible to determine the extent to which the results should be generalized to participants from other racial and ethnic backgrounds. 
A third limitation relates to the basic approach to qualitative data analysis used in this study. This basic approach was used due to the limited dataset available. A more in-depth qualitative data analysis process should be considered for future research with more extensive data. Finally, all data were self-reported by participants, and therefore it was not possible to determine the extent to which participants' descriptions of their beliefs and actions related to advocacy aligned with the experiences of others impacted by their advocacy actions. For example, a participant could view their actions as helpful (e.g., by providing advice to others in abusive relationships), but those actions may not be viewed in the same way by the people who were impacted by the actions or advice. Thus, future research would benefit from including data drawn from multiple perspectives and sources.

\section{Implications for Future Research}

This study represents the first known examination of the experiences and beliefs about advocacy among survivors of IPV. As such, further research is needed to provide more in-depth information about what it is like for survivors to engage in this type of activity. Attention should be paid to the strengths, challenges, and opportunities that survivors may encounter when acting as advocates for social change. Future research could also focus on more inclusive samples of individuals with intersecting minority identities in order to further contextualize perceptions of and possibilities for advocacy, as well as the unique advocacy issues and barriers to advocacy work faced by these populations. In this study, participants who responded to the advocacy question included a higher proportion of participants in the higher levels of household income. Within a social justice framework, this finding warrants further consideration in future research, particularly because it suggests that engaging in advocacy may in itself be viewed as a privileged practice that is most accessible to survivors of intimate partner violence who have greater access to financial resources and other social capital. Thus, an important implication for future research is how to best engage participants with lower levels of social capital in opportunities to have their voices heard through advocacy efforts.

In addition, researchers can consider the impacts of survivors' advocacy efforts, including the impacts on communities, other survivors, and the advocates themselves. In particular, researchers can examine what role advocacy activities may play in promoting survivors' experiences of overcoming their past abuse. Another important future direction for research is to examine counseling strategies that help to promote safe, effective advocacy engagement among survivors. As counselors have only recently begun to pay more attention to developing advocacy competencies within the counseling profession (Lewis et al., 2002), greater attention also is needed to how counselors can support client populations when they engage in this type of work. Special attention should be paid to ethical issues, such as dual relationships and confidentiality, especially if there are opportunities for counselors to partner with survivors and other client populations to advocate for social changes in their local communities. Another related direction for future research is to consider counselors who are themselves survivors of IPV, and how this may inform their practice related to both counseling and advocacy that addresses IPV. In this regard, a focus on self-care and countertransference issues should be addressed. Overall, a great need exists for research on advocacy initiatives within the counseling profession, and this should include advocacy that is carried out by counselors, as well as the client populations they serve. 


\section{Implications for Practice}

The ACA Advocacy Competencies (Lewis et. al, 2002) provide a useful framework for counselors who engage in any advocacy efforts that impact the client populations they serve. The Competencies touch upon the role of counselors in supporting clients in advocating for themselves. However, this remains an area where minimal research and few practical guidelines exist currently. As such, future attention should be paid to identifying appropriate and effective practice guidelines for counselors who want to promote this type of self-advocacy among the clients they serve. Counseling professionals who work to address social issues and advance advocacy practices within the profession may begin working toward developing a parallel set of advocacy competencies or practices that apply to advocacy efforts of client populations with whom counselors work. The ACA Advocacy Competencies are relevant to client populations who have experiences of oppression and are useful for identifying approaches to addressing the influences within clients' social contexts that contribute to barriers to their wellbeing (Ratts \& Hutchins, 2009). However, because the ACA Advocacy Competencies were developed to build upon professional counselors' unique training and practical experiences (Lewis et al., 2002), they should be modified to fit the more diverse professional backgrounds of client populations who do not have training in counseling methods.

Especially when working with client populations that have faced oppression and/or trauma, such as survivors of IPV, these practice guidelines should focus on the safety and emotional health of clients (Murray \& Graves, 2012). On a related note, the current study has implications for counselors working with clients who have experienced IPV and who are considering whether or how to engage in advocacy efforts. Counselors should adopt a trauma-informed care framework (SAMHSA, 2014) and create a safe, supportive context for clients to explore these issues and, if they decide to move forward with advocacy work, create a plan for how to do so safely. Counselors can help their clients explore whether they may experience emotional distress as they talk about abuse-and especially their own personal experiences with it-with others or are presented with triggering information. Clients who experience emotional distress as they engage in advocacy efforts may desire to continue their advocacy work, and counselors can help them consider ways to do so safely and indicators that they may need to take a break from this work. A final practice implication is for counselors to help clients who want to engage in advocacy but do not feel equipped to do so to identify opportunities for developing the skills and personal characteristics to do so. This may involve referrals to coursework, training opportunities, or reading materials that address the skills that can be useful in advocacy efforts (e.g., writing and public speaking).

In sum, survivors can play an important role in advocacy efforts to raise awareness about IPV, prevent future abuse, support survivors, and hold offenders accountable. These efforts may occur in partnership with counselors, or counselors can provide support to survivors who are clients as they engage in this work. The current study highlighted some important considerations for this population, including the importance of emotional safety and the diversity of opportunities available for survivors to engage in advocacy efforts. By adapting the ACA Advocacy Competencies (Lewis et. al, 2002) to their efforts to support survivors of IPV in their decisions about whether and how to engage in advocacy efforts, counselors have the opportunity to help survivors draw upon their past experiences with abuse to affect social changes that promote nonviolence and support survivors in their communities. 


\section{Author Contact Information}

Christine E. Murray, Ph.D., LPC, LMFT

Department of Counseling and Educational Development

The University of North Carolina at Greensboro

Email: cemurray@uncg.edu

\section{References}

Black, M.C., Basile, K.C., Breiding, M.J., Smith, S.G., Walters, M.L., Merrick, M.T., Chen, J., \& Stevens, M.R. (2011). The National Intimate Partner and Sexual Violence Survey (NISVS): 2010 Summary Report. Atlanta, GA: National Center for Injury Prevention and Control, Centers for Disease Control and Prevention. Retrieved November 3, 2014, from http://www.cdc.gov/violenceprevention/pdf/nisvs_executive_summary-a.pdf.

Centers for Disease Control and Prevention (CDC, 2014). Intimate partner violence: Definitions. Retrieved November 3, 2014, from http://www.cdc.gov/violenceprevention/intimatepartnerviolence/definitions.html.

Crowe, A., \& Murray, C. E. (2015). Stigma from professional helpers toward survivors of intimate partner violence. Partner Abuse, 6(2), p. 157-179.

Hsieh, H., \& Shannon, S. (2005). Three approaches to qualitative content analysis. Qualitative Health Research, 15, 1277-1288. DOI: 10.1177/1049732305276687

Lewis, J. A., Arnold, M. S., House, R., \& Toporek, R. L. (2002). ACA Advocacy Competencies. Retrieved May 20, 2014, from http://www.counseling.org/docs/competencies/advocacy_competencies.pdf?sfvrsn=3.

Morgan, M., \& Coombes, L. (2013). Empowerment and advocacy for domestic violence victims. Social and Personality Psychology Compass, 7(8), 526-536.

Murray, C. E., \& Crowe, A. (in press). The impact of stigma on survivors of intimate partner violence: Implications for counseling. In R. Javier \& W. Herron (Eds.), Domestic violence (pp. \#\#). New York: Jason Aronson (An imprint of Rowman \& Littlefield).

Murray, C. E., \& Crowe, A. (under review). Counseling advocacy competencies in action: Lessons learned through the See the Triumph campaign. 
Murray, C. E., Crowe, A., \& Akers, W. (in press). How can we end the stigma surrounding domestic and sexual violence? A modified Delphi study with national advocacy leaders. Journal of Family Violence.

Murray, C. E., Crowe, A., \& Brinkley, J. (2015). The stigma surrounding intimate partner violence: A cluster analysis study. Partner Abuse, 6, 320-336.

Murray, C. E., Crowe, A., \& Overstreet, N. (under review). Sources and components of stigma experienced by survivors of intimate partner violence. Murray, C. E., \& Graves, K. N. (2012). Responding to family violence. New York: Routledge.

Patton, M. (2002). Qualitative research and evaluation methods ( $3^{\text {rd }}$ ed.). Thousand Oaks, CA: Sage.

Ratts, M. J., \& Hutchins, A. (2009). ACA advocacy competencies: Social justice advocacy at the client/student level. Journal of Counseling \& Development, 87(3), 269-275. doi:10.1002/j.1556-6678.2009.tb00106.x

Stemler, S (2001). An overview of content analysis. Practical Assessment, Research \& Evaluation, 7(17). Retrieved May 16, 2012 from http://PAREonline.net/getvn.asp?v=7\&n=17.

Substance Abuse and Mental Health Services Administration (SAMHSA, 2014). Trauma-informed approach and trauma-specific interventions. Retrieved November 3, 2014, from http://www.samhsa.gov/nctic/trauma-interventions.

Toporek, R. L., Lewis, J. \& Crethar, H. C. (2009). Promoting systemic change through the Advocacy Competencies. Special Section on ACA Advocacy Competencies. Journal of Counseling and Development, 87,260-268. 